\title{
ANALISIS NILAI TAMBAH DAN TINGKAT PRODUKTIVITAS KERJA SERTA STRATEGI PENGEMBANGAN HOME INDUSTRY GULA KELAPA DI DESA TEMBOKREJO KECAMATAN GUMUKMAS KABUPATEN JEMBER
}

\section{ANALYSIS OF ADDITIONAL VALUE AND LEVEL OF WORK PRODUCTIVITY AND HAND COCONUT HOME INDUSTRY DEVELOPMENT STRATEGY IN THE VILLAGE OF TEMBOKREJO SUB DISTRICT GUMUKMAS DISTRICT JEMBER}

\author{
Yohana Tyas Sulistiowati*, Joni Murti Mulyo Aji*, dan Rudi Hartadi* \\ Program Studi Agribisnis Fakultas Pertanian Universitas Jember \\ E-mail:yohanatyas83@yahoo.co.id
}

\begin{abstract}
ABSTRAK
Home industry gula kelapa di Desa Tembokrejo melakukan pengolahan nira menjadi gula kelapa. Penelitian ini bertujuan untuk mengetahui (1) Nilai tambah pada home industry gula kelapa di Desa Tembokrejo, (2) tingkat produktivitas kerja home industry gula kelapa di Desa Tembokrejo (3) Strategi pengembangan home industry gula kelapa di Desa Tembokrejo. Penentuan daerah penelitian dilakukan secara sengaja (Purposive Method), yaitu di Desa Tembokrejo Kecamatan Gumukmas Kabupaten Jember. Metode penelitian yang digunakan adalah metode deskriptif dan analitis, dan metode pengambilan contoh yang digunakan adalah Total Sampling. Metode pengumpulan data menggunakan teknik wawancara dan observasi. Jenis data yang digunakan adalah data primer dan data sekunder. Analisa yang digunakan adalah analisis nilai tambah, analisis produktivitas kerja, analisis SWOT dan QSPM. Hasil penelitian menunjukkan: (1) Nilai tambah pada home indutry gula kelapa di Desa Tembokrejo adalah Rp 1.637,04/kg. (2) Tingkat produktivitas kerja home industry gula kelapa adalah rendah yaitu sebesar Rp 5.858/jam. (3) Strategi pengembangan home industry gula kelapa berada pada posisi White Area. (4) QSPM diperoleh prioritas strategi home industry gula kelapa dengan nilai Total Attractiveness Score (TAS) sebesar 6,13 yaitu meningkatkan produksi gula kelapa.
\end{abstract}

Kata Kunci: gula kelapa, nilai tambah, produktivitas kerja, SWOT, QSPM

\section{ABSTRACT}

Home industry of coconut sugar in Tembokrejo village to process palm sugar into coconut. The purpose of this research is to know (1) Value added at home industry of coconut sugar in Tembokrejo village, (2) productivity level of home industry of coconut sugar in Tembokrejo village (3) strategy of coconut industry home development in Tembokrejo Village. Determination of research area is done intentionally (Purposive Method), that is in Tembokrejo Village District Gumukmas Jember Regency. The research method used is descriptive and analytical method, and sampling method used is Total Sampling. Methods of data collection using interview and observation techniques. The type of data used is primary data and secondary data. The analysis used is valueadded analysis, work productivity analysis, SWOT and QSPM analysis. The results showed: (1) Value added on home indutry of coconut sugar in Tembokrejo village was Rp 1,637,04 / $\mathrm{kg}$. (2) The productivity level of coconut industry home work is low ie IDR 5.858 / hour. (3) The development strategy of coconut sugar home industry is in White Area position. (4) QSPM obtained the priority of coconut industry home industry strategy with Total Attractiveness Score (TAS) value of 6,13 that is increasing coconut sugar production.

Keyword: coconut sugar, added value, work productivity, SWOT, QSPM 


\section{PENDAHULUAN}

Pertanian di Indonesia terdiri dari berbagai macam sub-sektor, antara lain adalah sub-sektor peternakan, sub-sektor perikanan, dan sub-sektor perkebunan. Perkebunan secara umum merupakan suatu usaha budidaya tanaman baik oleh pemerintah, swasta, rakyat, maupun secara bersama-sama dalam skala luas maupun sempit areal lahan yang digunakan namun bertujuan untuk peningkatan pendapatan dan devisa negara tanpa mengabaikan penyerapan tenaga kerja dan pelestarian sumber daya alam. Strategi pengembangan peningkatan produksi perkebunan tidak lagi diletakkan pada intensifikasi saja sebagai titik berat, tetapi secara simultan berwawasan diversifikasi, intensifikasi, ekstensifikasi, dan rehabilitasi (Syamsulbahri, 1996).

Kelapa merupakan salah satu komoditas perkebunan. Salah satu produk diversifikasi nira adalah gula kelapa. Salah satu penghasil gula kelapa di Kabupaten Jember yaitu Desa Tembokrejo Kecamatan Gumukmas Kabupaten Jember. Desa Tembokrejo adalah salah satu desa yang memiliki potensi dalam usaha mengolah gula kelapa. Desa Tembokrejo didukung oleh kondisi desa yang pada setiap pekarangan rumah, sawah, dan tanah pinggir jalan ditumbuhi banyak pohon kelapa.

Kelapa diharapkan mampu memberikan sumbangan yang cukup besar bagi peningkatan dan kesejahteraan penduduk di Desa Tembokrejo. Usaha tersebut digunakan sebagai mata pencaharian sampingan. Adanya kondisi harga jual buah kelapa yang tidak stabil menyebabkan keresahan dalam menjalankan usahatani tersebut, dimana keuntungan yang mereka dapat menjadi berkurang. Oleh karena itu peningkatan keuntungan perlu dilakukan dengan adanya nilai tambah pada produk olahan pada bagian pohon kelapa, dimana mereka mulai memikirkan untuk memanfaatkan nira untuk dijadikan produk baru yang memiliki harga jual yang lebih tinggi, memiliki waktu penyimpanan yang lebih lama dan mampu untuk mencukupi kebutuhan hidup sehari-hari. Adanya proses pengolahan ini mampu untuk memenuhi kebutuhan sehari-hari karena proses produksi yang dilakukan setiap hari dan langsung dijual kepada tengkulak.

Pengrajin memanfaatkan nira sebagai bahan baku utama yang diolah menjadi gula kelapa untuk memperoleh keuntungan lebih. Proses pengambilan nira di sebut dengan penderesan. Kepemilikian pohon yang dimiliki oleh pengrajin gula kelapa di Desa Tembokrejo ini di bagi menjadi dua yaitu pohon milik sendiri dan pohon sewa, dimana pada pohon sewa pengrajin membayar satu pohon per bulannya seharga 2 kilogram gula kelapa atau sebesar Rp 26.000,00.

Home industry gula kelapa di Desa Tembokrejo mampu menyerap tenaga kerja dalam proses pengolahan nira menjadi gula kelapa. Karena faktor ekonomi yang rendah maka tenaga kerja yang digunakan adalah tenaga kerja dalam keluarga sehingga tidak diperlukan biaya untuk membayar tenaga kerja maka sebenarnya pendapatan yang mereka peroleh bukan dalam bentuk upah melainkan penghasilan rumah tangga tanpa ada pembagian untuk masing-masing tenaga kerja. Produktivitas setiap tenaga kerja akan menghasilkan output untuk home industry. Setiap tenaga kerja yang bekerja ingin mendapatkan upah dari home industry tersebut. Home industry akan menilai kinerja pekerja dari output tersebut sehingga home industry dapat mengetahui seberapa besar upah yang akan diberikan kepada tenaga kerja. Output tenaga kerja adalah pendapatan, pendapatan yang diterima oleh tenaga kerja ini mampu memberikan kontribusi untuk kebutuhan ekonomi rumah tangga. Untuk melihat tingkat produktivitas kerja pada home industry gula kelapa maka harus dilihat juga UMK (Upah Minimum Kabupaten) Jember sebagai acuan untuk menentukan tinggi atau rendahnya produktivitas kerja pada home industry gula kelapa di Desa Tembokrejo.

Home industry gula kelapa di Desa Tembokrejo ini memiliki kelemahan yaitu 
pemasaran terbatas, kemasan sederhana, teknologi sederhana, tenaga kerja dan modal. Pemasaran terbatas disebabkan karena keterikatan pengrajin dengan tengkulak, kemasan yang sederhana karena kegiatan usaha masih bersifat sederhana dan teknologi yang digunakan masih bersifat tradisional, tenaga kerja yang terbatas hanya menggunakan tenaga kerja dalam rumah untuk meminimalisir pengeluaran, keterbatasan modal pengrajin sehingga meminjam modal kepada tengkulak dengan sistem ijon ini membatasi pengrajin dalam melakukan pemasaran. Adanya kelemahan yang dihadapi oleh pengrajin gula kelapa ini tidak memutuskan harapan pengrajin dalam melakukan usaha gula kelapa. Keputusan pengrajin untuk tetap melakukan usaha gula kelapa di Desa Tembokrejo dikarenakan beberapa faktor yang mendukung dalam kegiatan home industry gula kelapa. Pengrajin gula kelapa di Desa Tembokrejo beranggapan bahwa dengan melakukan usaha home industry gula kelapa merupakan salah satu cara untuk memperoleh penghasilan yang lebih baik untuk memenuhi kebutuhan hidup. Pengrajin beranggapan bahwa dengan home industry gula kelapa memiliki peluang tinggi dengan memanfatkan ketersediaan bahan baku nira kelapa yang kemudian diolah menjadi gula kelapa dapat memberikan keuntungan. Berdasarkan permasalahan yang terjadi maka akan mempengaruhi proses pengembangan home industry gula kelapa di Desa Tembokrejo. Proses pengembangan home industry gula kelapa di Desa Tembokrejo didukung oleh faktor internal dan faktor eksternal. Kelemahan dan ancaman yang terjadi di Desa Tembokrejo merupakan faktor yang menghambat dalam proses pengembangan home industry gula kelapa. Maka dari itu perlu dilakukan berbagai upaya dan strategi pengembangan pada home industry ini agar mampu untuk terus berproduksi dan berkembang.

Berdasarkan pada latar belakang permasalahan tersebut maka diperlukan kajian sebagai bahan pertimbangan untuk perkembangan home industry gula kelapa dimasa akan datang dengan menganalisis nilai tambah yang di hasilkan dari produk gula kelapa, dan menganalisis tingkat produktivitas kerja sehingga dapat dilanjutkan dengan merumuskan strategi pengembangan usaha dengan melihat faktok internal dan faktor eksternal dengan menggunakan analisis Swot dan QSPM yang dapat dirancang pada home industry gula kelapa di Desa Tembokrejo Kecamatan Gumukmas.

Adapun tujuan dari penelitian, yaitu : (1) untuk mengetahui nilai tambah home industry gula kelapa di Desa Tembokrejo Kecamatan Gumukmas Kabupaten Jember, (2) untuk mengetahui tingkat produktivitas kerja pada home industry gula kelapa di Desa Tembokrejo Kecamatan Gumukmas Kabupaten Jember, (3) untuk mengetahui strategi pengembangan home industry gula kelapa di Desa Tembokrejo Kecamatan Gumukmas Kabupaten Jember.

\section{METODE PENELITIAN}

Metode yang digunakan dalam penelitian ini adalah metode deskriptif dan analitis. Metode deskriptif merupakan suatu metode untuk membuat deskriptif atau gambaran secara sistematis, faktual dan akurat mengenai fakta-fakta dan sifat-sifat fenomena yang diselidiki untuk mendapatkan kebenaran menerangkan hubungan dan menguji hipotesis sehingga memperoleh makna. Metode analitis adalah untuk menguji hipotesis-hipotesis dan mengadakan interpretasi yang lebih dalam (Nazir, 2009).

Penentuan daerah penelitian ini dilakukan dengan sengaja (purposive methode) yaitu di Desa Tembokrejo Kecamatan Gumukmas Kabupaten Jember. Pengambilan contoh yang digunakan adalah total sampling. Responden yang digunakan adalah sebanyak 16 orang (Sugiyono, 2005).

Metode pengumpulan data yang digunakan dalam penelitian ini terdiri dari: (1) Data primer yaitu data yang dikumpulkan secara langsung oleh peneliti pada responden 
dengan melakukan wawancara dan observasi secara langsung berdasarkan pada kuisioner yang dibuat peneliti. (2) Data sekunder yaitu sumber data diperoleh dari insatansi atau Dinas yang terkait dengan home industry gula kelapa, metode yang digunakan adalah metode dokumentasi dengan hasil data.

Metode analisis data yang digunakan adalah sebagai berikut:

Permasalahan pertama mengenai analisis nilai tambah home industry gula kelapa di Desa Tembokrejo Kecamatan Gumukmas Kabupaten Jember dalam satu kali produksi dapat dianalisis dengan metode hayami (Sudiyono,2002):

$$
\begin{aligned}
& \text { Nilai Tambah = } \mathrm{f}(\mathrm{K}, \mathrm{B}, \mathrm{T}, \mathrm{U}, \mathrm{H}, \mathrm{h}, \mathrm{L}) \\
& \text { Keterangan : } \\
& \mathrm{K} \quad \text { = Kapasitas produksi } \\
& \mathrm{B} \quad \text { = Bahan baku yang digunakan } \\
& \mathrm{T} \quad \text { = Tenaga kerja yang digunakan } \\
& \mathrm{U} \quad=\text { Upah tenaga kerja } \\
& \mathrm{H} \quad \text { = Harga output } \\
& \mathrm{h} \quad=\text { Harga bahan baku } \\
& \mathrm{L} \quad \text { = Nilai input (nilai dari semua } \\
& \quad \text { korbanan selama proses produksi) } \\
& \text { Besarnya nilai tambah diperoleh dari } \\
& \text { pengurangan biaya bahan baku dan input lain } \\
& \text { terhadap nilai produk yang dihasilkan, tidak } \\
& \text { termasuk tenaga kerja. Dengan kata lain, nilai } \\
& \text { tambah menggambarkan imbalan bagi tenaga } \\
& \text { kerja, modal dan manajemen. Sistematika } \\
& \text { perhitungan nilai tambah dipermudah dengan } \\
& \text { perhitungan pada Tabel 1. }
\end{aligned}
$$

Tabel 1. Metode Hayami

\begin{tabular}{llcc}
\hline No & Output, Input, Harga & Satuan & Formula \\
\hline 1. & Output & $(\mathrm{kg} / \mathrm{produksi})$ & \\
2. & Input Bahan Baku (Nira) & $(\mathrm{kg} / \mathrm{produksi})$ & \\
3. & Input Tenaga Kerja & $(\mathrm{jam} / \mathrm{produksi})$ & $(1) /(2)$ \\
4. & Faktor Konversi & & $(3) /(2)$ \\
5. & Koefisien Tenaga Kerja & $(\mathrm{Rp} / \mathrm{kg})$ & \\
6. & Harga Produk (Gula Kelapa) & $(\mathrm{Rp} / \mathrm{jam})$ & \\
7. & Upah Tenaga Kerja & $(\mathrm{Rp} / \mathrm{kg})$ & $(4) \mathrm{x}(6)$ \\
\hline Penerimaan dan Keuntungan Per Kilogram Bahan Baku & $(10)-(8)-(9)$ \\
\hline 8. & Input Bahan Baku (Nira) & $(\mathrm{Rp} / \mathrm{kg})$ & $\%(11) /(10)$ \\
9. & Input lainnya (selain TK) & $(\mathrm{Rp} / \mathrm{kg})$ & $(5) \mathrm{x}(7)$ \\
10 & Produksi & $(\mathrm{Rp} / \mathrm{kg})$ & $\%(12) /(11)$ \\
11 & Nilai Tambah & $\%$ & $(11)-(12)$ \\
& Rasio Nilai Tambah & $(\mathrm{Rp} / \mathrm{kg})$ & $\%(13) /(10)$ \\
12 & Pendapatan Tenaga Kerja & $\%$ & \\
& Pangsa Tenaga Kerja & $(\mathrm{Rp} / \mathrm{kg})$ & $\%$ \\
\end{tabular}

Sumber: Purnomowati dalam Sudiyono (2002)

Produktivitas kerja home industry gula kelapa di Desa Tembokrejo, menggunakan analisis statistik pendekatan produktivitas sebagai berikut (Umar, 1997).

$$
\text { Produktivitas Kerja }=\frac{\text { Dutput }}{\text { Input }}
$$

Untuk mengetahui tingkat produktivitas kerja pada home industry gula kelapa yaitu dengan membandingkan antara rata-rata poduktivitas kerja pada home industry dengan produktivitas kerja UMK (Upah Minimum Kabupaten) dengan rumus: 
Produktivitas Kerja $($ Rp/jam $)=$

$$
\text { Output(Rp/bulan) }
$$

Produktivitas UMK = UMK (Rp fbulan

jumlah jam kerja (jam Kerja,bulan)

Kriteria pengambilan keputusan:

1. Jika rata-rata produktivitas kerja $\geq$ ratarata produktivias UMK Jember maka tingkat produktivitas kerja adalah tinggi.

2. Jika rata-rata produktivitas < rata-rata produktivitas UMK Jember maka produktivitas kerja adalah rendah.

Strategi pengembangan home industry gula kelapa di Desa Tembokrejo menggunakan analisis SWOT. Menurut Rangkuti (2000) SWOT analisis yang menganalisis identifikasi berdasarkan berbagai faktor yaitu faktor internal terdiri dari kekuatan dan kelemahan, faktor eksternal terdiri dari peluang dan ancaman.

Faktor internal dan eksternal yang telah ditentukan berdasarkan observasi lapang kemudian dilakukan pembobotan pada masing-masing faktor. Langkah selanjutnya dilakukan rating dan pemberian jumlah nilai pada internal dan eksternal faktor. Nilai faktor Ifas dan Efas pada home industry gula kelapa menunjukkan posisi usaha dalam matriks analisis SWOT.

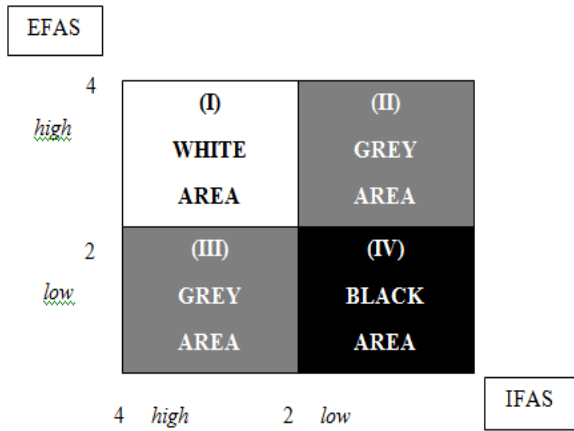

Gambar 1. Matrik Posisi Kompetitif Relatif

\section{Home Industry Gula Kelapa}

Berdasarkan nilai Ifas dan Efas yang telah didapatkan kemudian dapat dilihat posisi home industry pada gambar 2 .

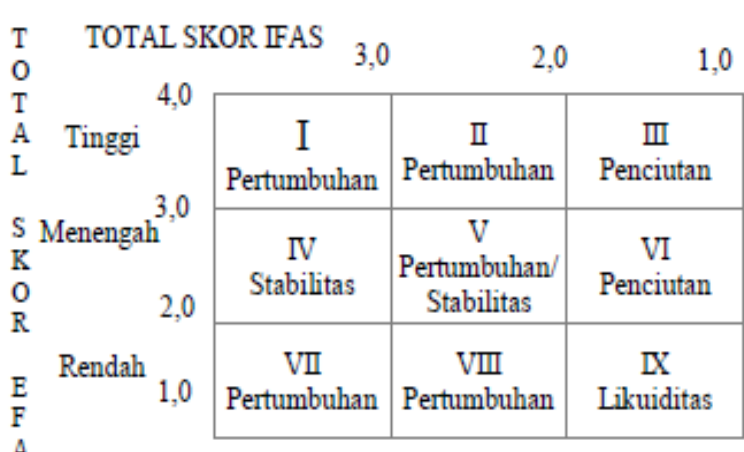

\section{Gambar 2. Matriks Internal dan Eksternal}

Tahap selanjutnya penentuan strategi dengan menggunakan analisis matriks SWOT. Matriks ini menggambarkan bagaimana peluang dan ancaman yang dimiliki agar sesuai dengan kekuatan dan kelemahan yang dimiliki home industry gula kelapa dengan menghasilkan empat sel alternatif strategi seperti pada Tabel 2. Sebagai berikut:

Tabel 2. IFAS dan EFAS

\begin{tabular}{|l|c|c|}
\hline IFAS & $\begin{array}{c}\text { Strength } \\
\mathrm{s}(\mathrm{S})\end{array}$ & $\begin{array}{c}\text { Weaknes } \\
\mathrm{s}(\mathrm{W})\end{array}$ \\
\hline EFAS & $\begin{array}{c}\text { Strategi } \\
\text { (SO) }\end{array}$ & $\begin{array}{c}\text { Strategi } \\
\text { (WO) }\end{array}$ \\
\hline Treaths (T) & $\begin{array}{c}\text { Strategi } \\
\text { (ST) }\end{array}$ & $\begin{array}{c}\text { Strategi } \\
\text { (WT) }\end{array}$ \\
\hline
\end{tabular}

Setelah itu dilanjutkan dengan melakukan analisis QSPM. Menurut David (2010), tujuan penggunaaan QSPM adalah untuk menentukan rekomendasi strategi yang dianggap tepat untuk diimplementasikan. QSPM menentukan daya tarik relatif dari berbagai strategi berdasarkan faktor internal dan eksternal. Daya tarik relatif dari setiap strategi dalam satu sel alternatif dihitung dengan menetapkan dampak kumulatif dari setiap faktor eksternal dan internal. menjadi pilihan terakhir, sehingga dapat dipilih strategi yang menjadi prioritas utama untuk di implementasikan pada home industry (David, 2010). 
Tabel 3. QSPM

\begin{tabular}{|c|c|c|c|c|c|}
\hline \multirow{3}{*}{ No } & \multirow[t]{3}{*}{ Faktor-faktor Sukses Kritis } & \multirow[t]{3}{*}{ Bobot } & \multicolumn{3}{|c|}{ Alternatif Strategi } \\
\hline & & & Strategi 1 & \multicolumn{2}{|c|}{ Strategi 2} \\
\hline & & & AS TAS & AS & TAS \\
\hline & Peluang & & & & \\
\hline 1. & Ketersediaan bahan baku & & & & \\
\hline \multirow[t]{2}{*}{2.} & Harga cukup tinggi & & & & \\
\hline & Ancaman & & & & \\
\hline 1. & Perubahan cuaca & & & & \\
\hline \multirow[t]{2}{*}{2.} & Persaingan mendapatkan bahan baku & & & & \\
\hline & Kekuatan & & & & \\
\hline 1. & Lokasi usaha & & & & \\
\hline \multirow[t]{2}{*}{2.} & Pengolahan relatif mudah & & & & \\
\hline & Kelemahan & & & & \\
\hline 1. & Kemasan sederhana & & & & \\
\hline 2. & Pemasaran produk & & & & \\
\hline 3. & Teknologi sederhana & & & & \\
\hline 4. & Tenaga kerja terbatas & & & & \\
\hline 5. & Modal terbatas & & & & \\
\hline \multicolumn{6}{|c|}{ Jumlah Total } \\
\hline Prio & Strategi & & & & \\
\hline
\end{tabular}

\section{PEMBAHASAN}

Nilai Tambah Home Industry Gula Kelapa Skala Kecil

Nilai tambah pada home industry gula kelapa merupakan pengolahan nira menjadi Tabel 4. Nilai Tambah per Kilogram Bahan Baku pada olahan gula kelapa pada home industry gila kelapa di Desa Tembokrejo.

\begin{tabular}{llrr}
\hline No. & Output, input dan harga & Formula & Nilai \\
\hline 1. & Output (kg/produksi) & & 13,57 \\
2. & Input Bahan Baku (kg/produksi) & & 40,71 \\
3. & Input Tenaga Kerja (jam/produksi) & $(1) /(2)$ & 8,35 \\
4. & Faktor Konversi & $(3) /(2)$ & 0,33 \\
5. & Koefisien Tenaga Kerja & & 0,21 \\
6. & Harga Produk (Rp/kg) & $9.000,00$ \\
7. & Upah Tenaga Kerja (Rp/jam) & & $2.000,00$ \\
Penerimaan dan Keuntungan (Rp/Kilogram nira kelapa) & \\
8. & Input Bahan Baku (Rp/kg) & & 385,00 \\
9. & Input lainnya(Rp/kg) & $(4)^{*}(6)$ & 977,96 \\
10 & Produksi (Rp/kg) & 3000,00 \\
11 & Nilai Tambah (Rp/kg) & 1637,04 \\
& Rasio Nilai Tambah(\%) & 54,57 \\
12 & Pendapatan Tenaga Kerja (Rp/kg) & $\%(11) /(10)$ & 410,39 \\
& Pangsa Tenaga Kerja (\%) & 25,07 \\
13 & Keuntungan (Rp/kg) & $\%(12) /(11)$ & $1.226,65$ \\
& Rate Keuntungan (\%) & $(11)-(12)$ & 40,89 \\
\hline
\end{tabular}

Sumber: Data Primer diolah, Tahun 2016

gula kelapa yang mampu menaikkan nilai produk. Penjelasan besarnya nilai tambah home industry gula kelapa di Desa Tembokrejo Kecamatan Gumukmas dapat dilihat pada Tabel 3. berikut : 
Berdasarkan Tabel 4. Menunjukkan bahwa home industry gula kelapa dalam satu kali produksi rata-rata mampu menghasilkan 13,57 kilogram gula kelapa dari 40,71 kilogram nira kelapa. Olahan nira pada home industry gula kelapa mampu memberikan nilai tambah sebesar Rp 1.637,04 per kilogram nira kelapa. Hal tersebut menunjukkan bahwa penerimaan home indsutry gula kelapa dari setiap kilogram nira yang diolah menjadi gula kelapa adalah Rp 1.637,04 atau sebesar 54,57 $\%$ dari nilai gula kelapa.

Faktor konversi merupakan nilai perbandingan antara gula kelapa yang dihasilkan dengan nira kelaa yang digunakan. Berdasarkan hasil dari perhitungan pada faktor konversi menunjukkan 1 kilogram nira kelapa akan menghasilkan 0,33 kiligram gula kelapa.
Rate keuntungan yang diperoleh sebesar $40,89 \%$ dari nilai produksi, artnya setiap 100 unit nilai produksi yang diproduksi akan memperoleh keuntungan sebanyak 40 unit.

\section{Tingkat Produktivitas Kerja Home Industry Gula Kelapa di Desa Tembokrejo Kecamatan Gumukmas Kabupaten Jember}

Pendapatan tenaga kerja merupakan output sedangkan keseluruhan jam kerja tenaga kerja adalah input. Untuk mengetahui tingkat produktivitas kerja maka dibandingkan dengan produktivitas UMK (Upah Minimum Kabupaten). UMK (Upah Minimum Kabupaten) Jember merupakan upah minimum daerah setempat yang diberikan kepada tenaga kerja selama kurun waktu tertentu.

Tabel 5. Rata-rata Jumlah Jam Kerja dan Hari Kerja pada Home Industry Gula Kelapa di Desa Tembokrejo Kecamatan Gumukmas Kabupaten Jember Tahun 2016.

\begin{tabular}{llccc}
\hline & & Jam & Hari & Jam \\
No & Uraian & Kerja/Hari & Kerja/Bulan & Kerja/Bulan \\
1. & UMK Jember & 8 & 26 & 208 \\
2. & Rata-rata TK Home Industry Gula Kelapa & 8,35 & 30 & 250,59
\end{tabular}

Sumber: Data Primer diolah, Tahun 2016

Berdasarkan Tabel 5. diketahui bahwa jumlah rata-rata jam kerja pada home industry gula kelapa adalah sebesar 250,59 jam/bulan, Satu hari kerja memiliki rata-rata 8,35 jam kerja. Angka tersebut menunjukkan bahwa nilai tersebut berada diatas standar yang telah ditetapkan oleh pemerintah daerah Kabupaten Jember yaitu dengan rata-rata jam kerja sebesar 208 jam/bulan dan 8 jam per hari.

Untuk mengetahui tingkat produktivitas kerja pada home industry gula kelapa yaitu dengan membandingkan poduktivitas kerja pada home industry gula kelapa di Desa Tembokrejo dengan produktivitas UMK pada tahun 2016 Upah Minimum Kabupaten Jember $=\operatorname{Rp~1.629.000:~}$

$$
\begin{aligned}
& \text { Produktivitas Kerja } \\
& \text { Output (Rp/bulan) } \\
& =\overline{\text { Input (jam Kerja fbulan) }} \\
& \underline{\text { Rp 1.487.052 }} \\
& =250,59 \mathrm{jam} \\
& =5.858 \mathrm{Rp} / \mathrm{jam} \\
& =\frac{\operatorname{Rp} 1.629000}{208 \mathrm{jam}} \\
& =7.832 \mathrm{Rp} / \mathrm{jam}
\end{aligned}
$$

Hasil perhitungan, dapat dilihat bahwa rata-rata produktivitas UMK Kabupaten Jember sebesar Rp. 7.832 per jam, sedangkan rata-rata produktivitas kerja pada home industry gula kelapa di Desa Tembokrejo 
sebesar Rp. 5.858 per jam. Berdasarkan kriteria pengambilan keputusan yang menyatakan bahwa Jika rata-rata produktivitas kerja $\geq$ rata-rata produktivias UMK Kabupaten Jember maka tingkat produktivitas kerja adalah tinggi dan Jika rata-rata produktivitas kerja < rata-rata produktivitas UMK Kabupaten Jember maka tingkat produktivitas kerja adalah rendah. Oleh karena itu, kriteria tingkat produktivitas kerja pada home industry gula kelapa di Desa Tembokrejo adalah rendah yaitu $5.858 \mathrm{Rp} / \mathrm{jam}<7.832 \mathrm{Rp} / \mathrm{jam}$.

\section{Strategi Pengembangan Home Industry Gula Kelapa di Desa Tembokrejo Kecamatan Gumukmas Kabupaten Jember}

\section{Analisis Faktor Strategi Internal dan Eksternal}

Desa Tembokrejo merupakan desa yang cukup dikenal oleh sebagian masyarakat sebagai desa yang berpotensi dalam pengolahan nira menjadi gula kelapa. Hal ini menyebabkan banyak penduduk di Desa Tembokrejo memilih bekerja sebagai pengrajin gula kelapa karena bahan baku yang bisa di dapat dengan mudah dan pengolahan yang mudah. Produksi dilakukan setiap hari oleh pengrajin. Semakin banyak nira kelapa yang yang digunakan maka semakin tinggi kapasitas produksi gula kelapa. Kapasitas minimum produksi gula kelapa yang di dapat dalam satu hari sebanyak 10 kilogram dan kapasitas produksi maksimum yang dihasilkan pekerja dalam satu hari sebanyak 25 kilogram, dan dengan rata-rata kapasitas produksi gula kelapa dalam satu hari adalah 17 kilogram. Kapasitas produksi minimum diakibatkan adanya keterbatasan modal, jumlah nira kelapa yang sedikit dan jam kerja yang digunakan dalam satu hari produksi gula kelapa relatif singkat.

Tabel 6. Analisis Faktor Strategi Internal Home Industry Gula Kelapa

\begin{tabular}{|c|c|c|c|c|}
\hline No & $\begin{array}{c}\text { Faktor Strategi } \\
\text { Internal }\end{array}$ & (S) & (W) & Komentar \\
\hline 1. & Lokasi usaha & $\mathrm{S}_{1}$ & & $\begin{array}{l}\text { 1. Lokasi usaha yang dekat dengan } \\
\text { bahan baku }\end{array}$ \\
\hline 2. & $\begin{array}{l}\text { Pengolahan } \\
\text { mudah }\end{array}$ & $\mathrm{S}_{2}$ & & $\begin{array}{l}\text { 2. Pengolahan gula kelapa yang } \\
\text { relatif mudah dan tidak } \\
\text { memerlukan keterampilan } \\
\text { khusus }\end{array}$ \\
\hline 3. & Pemasaran terbatas & & $\mathrm{W}_{1}$ & $\begin{array}{l}\text { 3. Pemasaran hanya pada } \\
\text { tengkulak saja }\end{array}$ \\
\hline 4. & Kemasan sederhana & & $\mathrm{W}_{2}$ & $\begin{array}{l}\text { 4. Kemasan yang masih standart } \\
\text { dan kurang menarik }\end{array}$ \\
\hline 5. & Teknologi sederhana & & $\mathrm{W}_{3}$ & 5. Menggunakan alat tradisional \\
\hline 6. & Tenaga kerja terbatas & & $\mathrm{W}_{4}$ & $\begin{array}{l}\text { 6. Tenaga kerja menggunakan } \\
\text { tenaga kerja dalam keluarga }\end{array}$ \\
\hline 7. & Modal terbatas & & $\mathrm{W}_{5}$ & $\begin{array}{l}\text { 7. Modal usaha dari pinjaman } \\
\text { tengkulak dengan melakukan } \\
\text { kesepakatan yang disebut ijon }\end{array}$ \\
\hline
\end{tabular}

Sumber: Data Primer diolah Tahun 2016

Tabel 6. Dapat diketahui terdapat faktorinternal yang mempengaruhi usaha home industry gula kelapa di Desa Tembokrejo.
Faktor-faktor tersebut terdiri dari kekuatan dan kelemahan dari home industry itu sendiri. Beberapa faktor lain yang dapat digunakan 
untuk mengembangkan home industry gula kelapa yaitu faktor eksternal. Faktor eksternal terdiri dari faktor peluang dan hambatan.
Faktor-faktor tersebut dapat dilihat pada Tabel 7. Sebagai berikut.

Tabel 7. Analisis Faktor Strategi Internal Home Industry Gula Kelapa

\begin{tabular}{|c|c|c|c|c|}
\hline No & $\begin{array}{c}\text { Faktor Strategi } \\
\text { eksternal }\end{array}$ & (O) & $(\mathbf{T})$ & Keterangan \\
\hline 1. & $\begin{array}{l}\text { Ketersediaan } \\
\text { bahan baku }\end{array}$ & $\mathrm{O}_{1}$ & & $\begin{array}{l}\text { 1. Bahan baku yang } \\
\text { melimpah dan mudah } \\
\text { didapat }\end{array}$ \\
\hline 2. & $\begin{array}{l}\text { Harga } \quad \text { cukup } \\
\text { tinggi }\end{array}$ & $\mathrm{O}_{2}$ & & $\begin{array}{l}\text { 2. Harga tinggi tetapi } \\
\text { masih terjangkau oleh } \\
\text { konsumen }\end{array}$ \\
\hline 3. & Perubahan Cuaca & & $\mathrm{T}_{1}$ & $\begin{array}{l}\text { 3. Perubahan cuaca } \\
\text { menyebabkan hasil nira } \\
\text { kelapa kurang baik }\end{array}$ \\
\hline 4. & $\begin{array}{l}\text { Persaingan } \\
\text { mendapatkan } \\
\text { bahan bakar }\end{array}$ & & $\mathrm{T}_{2}$ & $\begin{array}{l}\text { 4. Persaingan } \\
\text { mendapatkan bahan } \\
\text { bakar ketika musim } \\
\text { hujan }\end{array}$ \\
\hline
\end{tabular}

Sumber: Data Primer diolah Tahun 2016

Berdasarkan Tabel 7. Dapat dilihat bahwa terdapat 4 faktor eksternal yang terdapat dalam home industry gula kelapa. Faktor peluang yaitu ketersediaan bahan baku dan harga cukup tinggi dan faktor ancaman yaitu perubahan cuaca dan persaingan mendapatkan bahan baku.

\section{Analisis Matriks Posisi Kompetitif Relatif}

Analisis posisi relatif merupakan alat analisis keadaan untuk mengetahui posisi home industry gula kelapa di Desa Tembokrejo. Hasil analisis faktor IFAS dan EFAS dari home industry gula kelapa di Desa Tembokrejo dilihat pada Tabel 8 sebagai berikut:.

Tabel 8. Analisis Skor IFAS dan EFAS Home

\begin{tabular}{cllc}
\multicolumn{4}{c}{ Industry Gula Kelapa } \\
\hline No. & \multicolumn{1}{c}{ Uraian } & Keterangan & NIlai \\
\hline 1. & Faktor & Kekuatan & 0,81 \\
& Internal & & \\
& & Kelemahan & 1,42 \\
\hline & Total IFAS & & 2,22 \\
\hline 2. & Faktor & Peluang & 1,33 \\
& Eksternal & &
\end{tabular}

\begin{tabular}{ccc} 
& Ancaman & 0,71 \\
\hline Total EFAS & 2,04 \\
\hline
\end{tabular}

Sumber: Data Primer diolah Tahun 2016

Berdasarkan Tabel 8. diketahui bahwa nilai IFAS sebesar 2,22 dan nilai EFAS sebesar 2,04 dari home industry gula kelapa yang didapatkan berdasarkan kondisi home industry. Nilai tersebut merupakan nilai yang diperoleh dari bobot yang telah dikonversi dikalikan dengan rating. Nilai tersebut dikonversi bertujuan untuk mensubjektifkan antara kekuatan dan kelemahan yang memiliki jumlah faktor yang berbeda. Nilai EFAS dan IFAS tersebut menunjukkan posisi home industry pada White Area, yaitu bidang kuat berpeluang. Berdasarkan analisis tersebut daat digambarkan ke dalam matriks kompetitif relatif pada gambar 3 . 


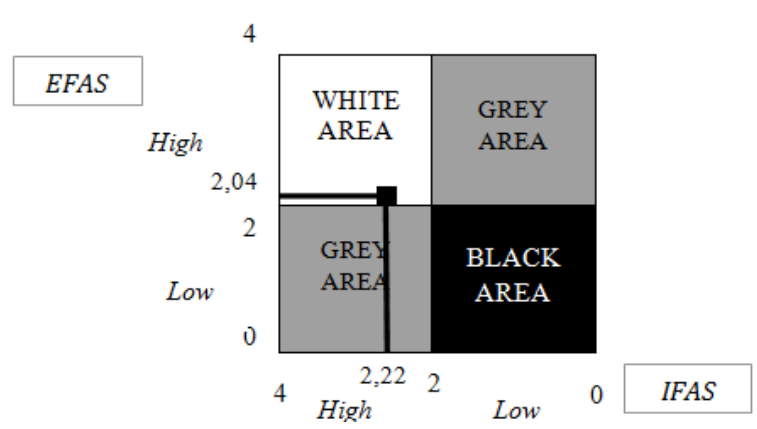

Gambar 3. Matriks Kompetitif Relatif Home Industry Gula Kelapa

Gambar 3 menjelaskan bahwa posisi home industry gula kelapa berada pada posisi White Area, yaitu bidang kuat berpeluang. Posisi ini menjelaskan bahwa home industry gula kelapa memiliki prospek yang baik, karena pada masuk dalam wilayah yang memiliki bidang kuat berpeluang untuk dilakukan. Berpeluang ini mampu memiliki peluang yang baik untuk mengembangkan usaha selanjutnya.

\section{Matrik Internal Eksternal}

Berdasarkan perhitungan yang dilakukan terhadap faktor-faktor dari kondisi internal dan eksternal pada home industry gula kelapa di Desa Tembokrejo dapat dihubungkan dengan matrik internal eksternal. Matrik internal dan eksternal terdapat sembilan sel. Berikut merupakan matrik internal eksternal home industry gula kelapa.

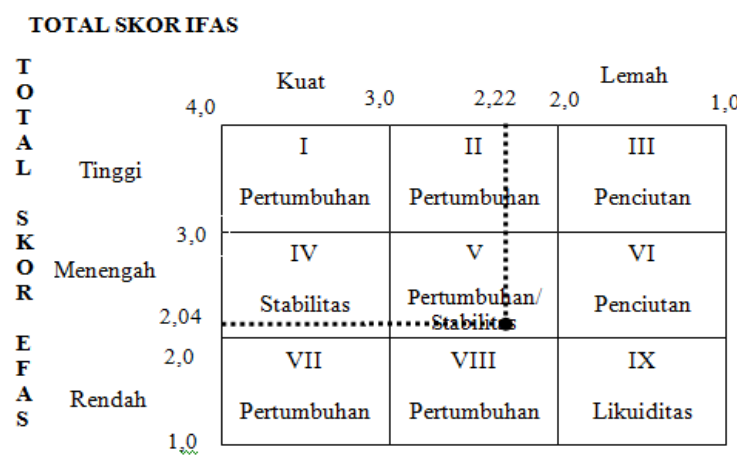

Gambar 4. Matrik Internal dan Eksternal Home Industry Gula Kelapa di Desa Tembokrejo

Berdasarkan gambar 4 menunjukkan bahwa letak home industry gula kelapa berada pada kuadran $\mathrm{V}$ dengan nilai faktor internal 2,22 dan nilai faktor eksternal 2,04. Hal tersebut mengakibatkan home industry gula kelapa masuk ke dalam daerah pertumbuhan/ stabilitas. Sehingga untuk mengembangkan dapat menggunakan strategi dengan memaksimalkan kekuatan dan peluang yang dimiloki home industry gula kelapa. Rancangan strategi home industry gula kelapa di Desa Tembokrejo dapat dilihat pada Gambar 5 sebagai berikut:

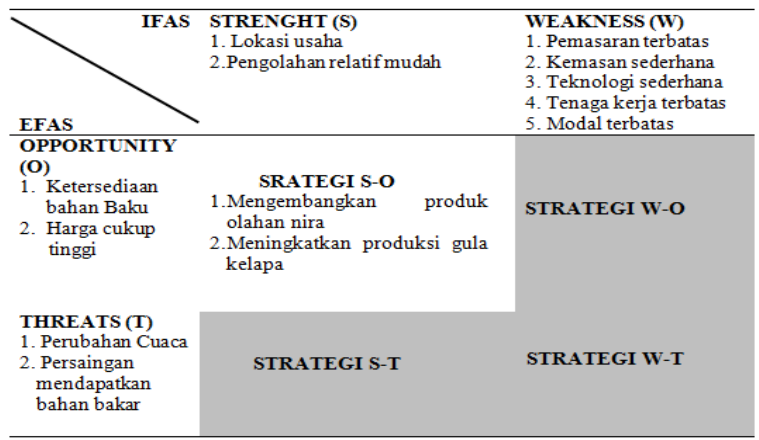

Gambar 5. Rancangan Strategi Home Industry gula kelapa

Berdasarkan Gambar 5 diketahui Strategi pertama yang dilakukan yaitu de-ngan mengembangkan produk olahan nira kelapa yaitu dengan menggunakan nira ke-lapa untuk di produksi menjadi gula kelapa, seharusnya pengrajin bisa mengembangkan produk nira kelapa untuk diolah menjadi gula semut dan gula kelapa cair. Dengan mengembangkan produk baru menggunakan bahan baku nira mampu menarik minat konsumen. Ketersediaan bahan baku di luar daerah dapat dijadikan sebagai peluang untuk memperluas produksi olahan nira kelapa. Strategi kedua yang digunakan untuk pengembangan home industry gula kelapa yaitu dengan meningkatkan produksi gula kelapa. Lokasi usaha yang dekat dengan bahan baku dan bahan baku yang mudah untuk dicari memudahkan home industry gula kelapa untuk meningkatkan produksinya. Dengan meningkatnya produk-si, pengrajin gula kelapa dapat meraih peluang pasar dengan harga jual gula kelapa yang lebih tinggi dibandingkan menjual kepada tengkulak.

\section{Analisis QSPM}

Menurut Purwanto (2006 bahwa Quantiative Strategy Planning Matrix (QSPM) 
analisis yang digunakan untuk menentukan kemenarikan relatif (Relative Attractiveness) dan mengevaluasi pilihan-pilihan strategi alternatif yang mampu dilakukan atau di implementasikan secara objektif, berdasarkan faktor-faktor sukses internal dan faktor-faktor sukses eksternal yang telah diidentifikasi sebelumnya. Berikut alternatif strategi pengembangan home industry gula kelapa di Desa Tembokrejo dapat dilihat pada Tabel 9:

Tabel 9. Prioritas Strategi Pengembangan Home Industry Gula Kelapa

\begin{tabular}{|c|c|c|c|c|c|c|}
\hline \multirow{3}{*}{ No } & \multirow[t]{3}{*}{ Faktor-faktor Sukses Kritis } & \multirow[t]{3}{*}{ Bobot } & \multicolumn{4}{|c|}{ Alternatif Strategi } \\
\hline & & & \multicolumn{2}{|l|}{ Strategi 1} & \multicolumn{2}{|c|}{ Strategi 2} \\
\hline & & & AS & TAS & AS & TAS \\
\hline & Peluang & & & & & \\
\hline 1. & Ketersediaan bahan baku & 0,25 & 4 & 0,92 & 3 & 0,84 \\
\hline \multirow[t]{2}{*}{2.} & Harga cukup tinggi & 0,25 & 3 & 0,82 & 4 & 0,86 \\
\hline & Ancaman & & & & & \\
\hline 1. & Perubahan cuaca & 0,22 & 3 & 0,73 & 3 & 0,60 \\
\hline \multirow[t]{2}{*}{2.} & $\begin{array}{l}\text { Persaingan mendapatkan } \\
\text { bahan baku }\end{array}$ & 0,28 & 3 & 0,74 & 3 & 0,79 \\
\hline & Kekuatan & & & & & \\
\hline 1. & Lokasi usaha & 0,13 & 2 & 0,31 & 3 & 0,41 \\
\hline \multirow[t]{2}{*}{2.} & Pengolahan relatif mudah & 0,15 & 3 & 0,49 & 4 & 0,54 \\
\hline & Kelemahan & & & & & \\
\hline 1. & Kemasan sederhana & 0,10 & 2 & 0,18 & 3 & 0,25 \\
\hline 2. & Pemasaran produk & 0,14 & 2 & 0,28 & 2 & 0,27 \\
\hline 3. & Teknologi sederhana & 0,17 & 3 & 0,57 & 3 & 0,60 \\
\hline 4. & Tenaga kerja terbatas & 0,15 & 2 & 0,36 & 3 & 0,38 \\
\hline 5. & Modal terbatas & 0,15 & 3 & 0,52 & 4 & 0,59 \\
\hline \multicolumn{3}{|c|}{ Jumlah Total } & 31 & 5,92 & 33 & 6,13 \\
\hline \multicolumn{3}{|c|}{ Prioritas Strategi } & Prioritas 2 & & \multicolumn{2}{|c|}{ Prioritas 1} \\
\hline
\end{tabular}

Sumber: Data Primer diolah Tahun 2016

Berdasarkan Tabel 9. dapat diketahui hasil QSPM menunjukkan bahwa strategi pertama memiliki total nilai daya tarik (TAS) sebesar 5,92 dengan strategi "Mengembangkan produk nira kelapa". Strategi kedua memiliki total nilai daya tarik (TAS) sebesar 6,13 dengan strategi "Meningkatkan produksi gula kelapa". Berdasarkan jumlah total nilai daya tarik dapat dilihat bahwa nilai pada strategi kedua lebih besar dibandingkan dengan strategi pertama. Hal ini menunjuk-kan bahwa strategi kedua lebih baik untuk di implementasikan dibandingkan dengan strategi pertama. Prioritas strategi yang dihasilkan pada tabel QSPM dari urutan terbesar sampai terkecil dalam pengemba-ngan home industry gula kelapa di Desa Tembokrejo, sebagai berikut: meningkatkan produksi gula kelapa $(6,13)$ dan mengem-bangkan produk olahan nira kelapa $(5,92)$.

\section{KESIMPULAN}

1. Pengolahan nira menjadi gula kelapa pada home industry gula kelapa di Desa Tembokrejo Kecamatan Gumukmas Kabupaten Jember memberikan nilai tambah. Nilai tambah home industry gula kelapa sebesar Rp 1637,04/kg bahan baku dengan rasio nilai tambah $54,57 \%$. 
2. Tingkat produktivitas kerja pada home industry gula kelapa di Desa Tembokrejo adalah rendah yaitu sebesar $5.858 \mathrm{Rp} / \mathrm{jam}$ sedangkan produktivitas kerja UMK Jember sebesar $7.832 \mathrm{Rp} / \mathrm{jam}$.

3. Berdasarkan nilai TAS tersebut maka dapat disimpulkan bahwa strategi yang terbaik untuk di implementasikan dan menjadi prioritas pertama pada home industry gula kelapa di Desa Tembokrejo Kecamatan Gumukmas adalah strategi kedua yaitu meningkatkan produksi gula kelapa.

\section{UCAPAN TERIMA KASIH}

Penulis mengucap terima kasih kepada Bapak Mustapit, S.P., M.Si dan Bapak M. Rondhi, S.P., M.P., Ph.D selaku dosen penguji yang telah memberikan masukan dan saran. Pak Rusman, Pak Sudar, Pak Saeroji, Pak Adi, Pak Heri, Pak Ribut, Pak Yanto A, Pak Muadi, Pak Amir, Pak Yanto B, Pak Rosadi, Pak Sumiran, Pak Soni, Pak Sarman, Pak Agus, Pak Tukirin selaku pemilik home industry gula kelapa yang telah memberikan informasi dan bantuan pada penelitian ini, juga pihak terkait yang telah membantu pelaksanaan penelitian.

\section{DAFTAR PUSTAKA}

David, F. R. 2010. Manajemen Strategis Konsep. Jakarta (ID): Salemba Empat.

Nazir. 2009. Metodologi Penelitian. Jakarta: Ghalia Indonesia.

Rangkuti, Freddy. 2003. Analisis SWOT Teknik Membedah kasus Bisnis. Jakarta: PT. Gramedia Pustaka Utama.

Sudiyono, A. 2002. Pemasaran Pertanian. Malang: Universitas Muhammadiyah Malang.

Sugiyono. 2005. Metode Penelitian Administratif. Bandung: Alfabeta.

Syamsulbahri. 1996. Bercocok Tanam Tanaman Perkebunan Tahunan. Yogyakarta: Gadjah Mada University Press 